\title{
Artur Rocha, A Muralha de D. Dinis e a Cidade de Lisboa. Fragmentos Arqueológicos e a Evolução Histórica
}

Paulo Almeida Fernandes

\section{(2) OpenEdition}

\section{Journals}

Edição electrónica

URL: http://journals.openedition.org/medievalista/1228

DOI: 10.4000/medievalista.1228

ISSN: 1646-740X

Editora

Instituto de Estudos Medievais - FCSH-UNL

\section{Refêrencia eletrónica}

Paulo Almeida Fernandes, «Artur Rocha, A Muralha de D. Dinis e a Cidade de Lisboa. Fragmentos Arqueológicos e a Evolução Histórica », Medievalista [Online], 20 | 2016, posto online no dia 01 dezembro 2016, consultado o 23 setembro 2020. URL : http://journals.openedition.org/medievalista/ 1228 ; DOI : https://doi.org/10.4000/medievalista.1228

\section{(c) (7) (5)}

Mediavalista está licenciado com uma Licença Creative Commons - Atribuição-NãoComercial 4.0 Internacional. 
Título / Title: Recensão: ROCHA, Artur - A Muralha de D. Dinis e a Cidade de Lisboa. Fragmentos Arqueológicos e a Evolução Histórica. Lisboa: Museu do Dinheiro / Banco de Portugal, 2015 (60 pp.)

Autor(es) / Author(s): Paulo Almeida Fernandes

Universidade / University: Universidade de Coimbra

Faculdade e Departamento / Unidade de Investigação - Faculty and Department /

Research Center: Centro de Estudos em Arqueologia, Artes e Ciências do Património (CEAACP)

Código Postal / Postcode: 3000-495

Cidade / City: Coimbra

País / Country: Portugal

Email: pauloalmeidafernandes@gmail.com

Fonte: Medievalista [Em linha]. Direc. Bernardo Vasconcelos e Sousa. Lisboa: IEM.

Disponível em:

http://www2.fcsh.unl.pt/iem/medievalista/MEDIEVALISTA20/fernandes2009.html ISSN: 1646-740X

Data de recepção do texto / Received for publication: 10 de Fevereiro de 2016 


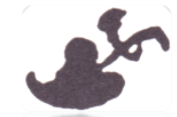

Recensão: ROCHA, Artur - A Muralha de D. Dinis e a

Cidade de Lisboa. Fragmentos Arqueológicos e a Evolução Histórica. Lisboa: Museu do Dinheiro / Banco de Portugal, 2015 (60 pp.).

\section{Paulo Almeida Fernandes}

Os livros não se medem pelos palmos da lombada ou da capa ${ }^{1}$. Nem as escavações arqueológicas se medem pelos palmos de metros cúbicos de terra movimentada. $\mathrm{O}$ desfecho da intervenção no subsolo da igreja de São Julião e da sede do Banco de Portugal, em Lisboa, com vista à adaptação parcial do edifício a Museu do Dinheiro, prova isso mesmo. À partida, tratava-se de mais uma intervenção arqueológica ditada por imperativos legais, a realizar num local situado na fronteira difusa da malha urbana medieval, zona periférica de urbanização tardia e cujas sedimentações históricas estariam potencialmente mais ligadas às remodelações que a cidade conheceu após o terramoto de 1755. Os resultados obtidos, todavia, vieram assegurar ao Museu do Dinheiro do Banco de Portugal um estatuto cimeiro, quer no panorama científico dos estudos dedicados à Lisboa medieval, quer nos itinerários arqueológicos da cidade que são parte importante da diferenciação turística de índole cultural da capital.

No Museu do Dinheiro trabalhou-se em segredo. O principal resultado - a identificação de um troço da muralha ribeirinha construída no reinado de D. Dinis - foi alcançado na campanha de 2010, mas o livro que evidencia a importância dessa descoberta e a integra nos mais vastos contextos topográficos e cronológicos da cidade ocorreu apenas mais de

\footnotetext{
${ }^{1}$ Para a redacção deste texto, quero manifestar o meu agradecimento a Catarina Tente (IEM/Univ. Nova de Lisboa), Lídia Fernandes (CML/Museu de Lisboa), Sara Barriga Brighenti e Artur Rocha (Museu do Dinheiro do Banco de Portugal) e Susana Serra (CML/EGEAC/Castelo de São Jorge).
} 
quatro anos depois daquele momento revelador, e sensivelmente um ano após a abertura ao público do Núcleo de Interpretação da Muralha de D. Dinis (Abril de 2014). Hoje, o que visitante pode visitar é um lanço de muralha com mais de 30 metros de comprimento, ao qual se acede descendo pouco mais de um andar, até uma cota que nos parece levar verdadeiramente ao coração subterrâneo da Baixa de Lisboa.

O livro não é apenas dedicado ao troço preservado da muralha dionisina. Na verdade, o seu autor, o arqueólogo Artur Rocha, conta várias histórias nesta publicação, mas fá-lo tendo em consideração o apertado espaço que escavou e os contextos históricos da própria cidade. Interessou-lhe, sobretudo, compreender os diferentes momentos da evolução de Lisboa e qual o contributo que os achados da escavação podiam trazer para esse panorama mais amplo, preocupação bem ilustrada no subtítulo do livro Fragmentos arqueológicos e evolução histórica. Por essa razão, o texto não prescinde de contar a própria história de Lisboa, desde os seus primeiros povoadores até às radicais alterações do período pombalino, constituindo-se um fluido e coerente discurso que se situa no âmbito da divulgação, porém sem abandonar as características próprias de uma edição científica, na qual a problematização de dados é uma constante.

Mas são mais os méritos desta obra. A principal virtude, quanto a mim, é revelar finalmente um troço da muralha do tempo de D. Dinis, obra militar há muito conhecida através da documentação - sobretudo pelo contrato de 1294, assente entre o monarca e o concelho de Lisboa, que permitiu a sua edificação -, mas cujo traçado e características construtivas permaneciam ocultos, não obstante os esforços de Augusto Vieira da Silva em reconstituir alguns aspectos estruturantes.

Em rigor, a muralha dionisina era já fisicamente conhecida, mas não em "ambiente científico controlado", como bem esclarece Artur Rocha ${ }^{2}$. Augusto Vieira da Silva havia já noticiado a descoberta de um troço no subsolo de um edifício na Rua do Comércio, n. ${ }^{\circ}$ s 112-114, paralelo à fachada do prédio $^{3}$, mas foi no Banco de Portugal que se registou a muralha através dos métodos científicos rigorosos ao serviço da moderna

\footnotetext{
${ }^{2}$ ROCHA, Artur - A Muralha de D. Dinis..., p. 28.

${ }^{3}$ SILVA, Augusto Vieira da - As Muralhas da Ribeira de Lisboa. 2. ${ }^{a}$ ed. Lisboa: Câmara Municipal de Lisboa, 1940, p. 35.
} 
arqueologia. E foi também aqui que se optou por preservar o "muro velho", ignorandose o que ocorreu em relação ao lanço identificado em 1939.

O estudo da muralha agora descoberta possibilitou a chegada a outras conclusões relevantes. Por um lado, permitiu caracterizar a técnica construtiva adoptada na edificação medieval, que recorreu ao uso sistemático de pedra miúda unida por abundante argamassa, tendo-se concluído os muros exteriores e interiores com capas de revestimento em argamassa obtidas através de um sistema de cofragem que pareceu algo descuidado ${ }^{4}$. Esta solução não deixa de surpreender, uma vez que são bem conhecidas as fortificações do tempo de D. Dinis que recorreram a aparelhos construtivos plenamente isódomos, realizados com silhares de apreciáveis dimensões, exemplarmente talhados e dispostos em fiadas regulares. No entanto, a variedade tipológica das construções militares medievais de Lisboa já tinha sido identificada por Lídia Fernandes, na intervenção que realizou na Escola Secundária Gil Vicente, tendo na altura identificado largos troços de taipa, ainda com vestígios de cofragem ${ }^{5}$. Por outro lado, o trabalho de Artur Rocha permitiu também corrigir ligeiramente o traçado da muralha proposto por Vieira da Silva, que idealizou uma progressão da estrutura no sentido Nordeste-Sudoeste, tendo sido agora possível perceber que ela se desenvolvia de Este para Oeste, quase em linha recta ${ }^{6}$, pelo menos no sector agora intervencionado.

Apesar dos muitos progressos constantes deste livro, os dados revelados sobre a muralha colocam muitas perguntas à comunidade científica que se dedica a estudar a Lisboa medieval. O troço identificado localiza-se no limite ocidental da cidade, zona de grande expansão entre os séculos XIII e XIV, mas também uma área presumivelmente fortificada ou, pelo menos, dotada de referências verticalizantes de carácter defensivo. São conhecidas as propostas de Augusto Vieira da Silva acerca da existência prévia ao amuralhamento do tempo de D. Dinis de umas tercenas fortificadas com pelo menos duas torres, a das Tercenas e a das Pombas (uma terceira torre, chamada de Maracote, está documentada apenas para o século XVI, como notou José de Vasconcellos e

\footnotetext{
${ }^{4}$ ROCHA, Artur - A Muralha de D. Dinis..., p. 29.

5 FERNANDES, Lídia - "A Muralha Fernandina de Lisboa: troço existente na Escola Gil Vicente Largo da Graça". Estudos Património, n. 5 (2003), p. 183.

${ }^{6}$ ROCHA, Artur - "Uma muralha, vários percursos". Revista Rossio, n. 3 (2014), p. 85.
} 
Menezes) $)^{7}$. Este dado é relevante porque a própria muralha devia articular-se com portas de acesso ao "campo que cobre a maré" (assim chamada a praia entre o rio e o muro dionisino num documento de 1302), mas a escavação não logrou identificar nenhum vão de passagem, nem qualquer das torres propostas por Vieira da Silva, pressentindo-se, também por esta via, uma certa simplicidade da estrutura que parece ter correspondência com a própria técnica construtiva.

Outras perguntas situam-se em âmbitos de maior exigência, que apenas a ampliação da área intervencionada arqueologicamente poderá vir a responder. Qual a relação da muralha dionisina com a Cerca Fernandina, construída escassos oitenta anos depois daquela? A crer no traçado proposto por Vieira da Silva para esta última, a opção dos construtores do século XIV foi a de inviabilizar a edificação do tempo de D. Dinis, que já aparece mencionada como "muro velho" num documento da chancelaria régia, datado de $1424^{8}$. Este dado leva-me a admitir que a empreitada fernandina terá registado diferentes escolhas ainda por explicar cabalmente: na zona ocidental da cidade, terá menosprezado a muralha dionisina mas, no extremo oposto, no lado oriental, aproveitou uma torre anterior ao tempo de D. Dinis para se ligar à Cerca Velha - em concreto a torre de S. Pedro, cuja primeira menção data de 1263. Por outro lado, qual a relação que se poderá estabelecer com o troço do muro dionisino identificado em 1939? Faria este ainda parte do sector de muralha promovido pelo rei, ou estaria já na área que a Câmara de Lisboa se comprometeu a construir pelo contrato de 1294, mas cuja empreitada não está provada? E teria o troço construído pela autarquia as mesmas características construtivas que o patrocinado pelo monarca?

Estas e muitas outras perguntas não podem ser dirigidas apenas à equipa de arqueologia do Museu do Dinheiro do Banco de Portugal. É necessário que outros agentes científicos possam prestar o seu contributo para que as perspectivas agora inauguradas de interpretação da muralha do reinado de D. Dinis possam ter continuidade em relação à totalidade do sistema defensivo medieval de Lisboa.

\footnotetext{
${ }^{7}$ MENEZES, José de Vasconcellos e - "Tercenas de Lisboa - II". Lisboa. Revista Municipal. 2. ${ }^{a}$ Série, n. 17 (1986), p. 11.

${ }^{8}$ SILVA, Augusto Vieira da - As Muralhas da Ribeira de Lisboa..., p. 30.
} 
Na verdade, a acção desenvolvida pelo Museu do Dinheiro não é a única iniciativa dedicada a desvendar e a preservar trechos do sistema muralhado medieval da cidade. Dois outros projectos em curso merecem ser aqui referenciados, pela grande importância dos resultados até agora alcançados.

O primeiro diz respeito ao trabalho de Manuela Leitão, cuja investigação desenvolvida ao longo de vários anos sobre a Cerca Velha culminou na constituição de um circuito pedonal de cerca de 1,5 Kms., sinalizado com 16 pontos de informação, e que permite a realização de uma visita orientada e informada de aproximadamente uma hora em torno daquele perímetro muralhado. Seguindo os vários painéis informativos, estrategicamente colocados em locais relevantes da muralha, que situam o visitante no circuito e fornecem-lhe informação contextual adicional, a visita pode ser complementada com um mapa que está disponível em alguns pontos turísticos, assim dispensando a orientação por parte de guias.

O itinerário da Cerca Velha foi inaugurado em Setembro de 2014 como produto turístico, mas ele representa a face mais visível de um programa de trabalhos de maior ambição. O PIEVCVL - Projecto Integrado de Estudo e Valorização da "Cerca Velha" de Lisboa $^{9}$, cujas origens recuam a 1998, promoveu a realização de 11 escavações, o levantamento criterioso de sete sectores de paramentos, duas acções de conservação e restauro e um plano coerente de qualificação urbanística da envolvente à cerca. Realizou-se mesmo um estudo de arqueologia da arquitectura, num dos trechos mais bem preservados (Rua da Judiaria e Postigo de São Pedro $)^{10}$, e um projecto de investigação específico destinado a caracterizar as argamassas, passo interdisciplinar decisivo para compreender técnicas construtivas e a produção de ligantes e revestimentos a partir dos recursos naturais existentes em Lisboa ${ }^{11}$.

\footnotetext{
${ }^{9}$ LEITÃO, Manuela - "Muralhas de Lisboa". Revista Rossio, n. 3 (2014), pp. 66-67.

${ }^{10}$ FONTES, Luís; MACHADO, André; CATALÃO, Sofia - Cerca Velha da rua da Judiaria e Torre de S. Pedro (Alfama). [Em linha]. Braga: Unidade de Arqueologia da Universidade do Minho, 2012. Disponível em https://www.uaum.uminho.pt/edicoes/revistas

${ }^{11}$ ALMEIDA, Luís Filipe de - Caracterização das argamassas da muralha tardo-romana de Olisipo. Lisboa: Faculdade de Ciências da Universidade de Lisboa, 2015. Projecto de Mestrado em Geologia Aplicada.
} 
Estes números impressionam pela abrangência de acções e novos dados serão revelados em breve (uma vez que continuam as sondagens, como a que a Marina Carvalhinhos efectuou na Rua Norberto Araújo, em 2015), mas a Cerca Velha, como qualquer marca arquitectónica de uma cidade em contínua transformação, é um organismo vivo que guarda partes da história de Lisboa por decifrar. A muralha não foi sempre uma fronteira; ela foi ponto de apoio e de partida para outras construções, foi rasgada e rompida para permitir acessos antes indesejados, foi alteada e suprimida ao sabor de vagas construtivas e gerações de vontades. A densa história que o projecto de estudo e valorização tem revelado, complementa-se com a documentação medieval, moderna e contemporânea e um crescente espólio iconográfico e fotográfico, ingredientes que adivinham a relevância e o sucesso de um centro interpretativo sobre este monumento (ambição antiga dos gestores do PIEVCVL), mas também de um livro sobre a Cerca Velha de Lisboa, não já um roteiro ou um circuito turístico-cultural, mas sim um estudo monográfico que sedimente o conhecimento adquirido até hoje.

O segundo projecto iniciou-se mais tarde, mas os primeiros resultados são bastante animadores. Na verdade, há muito tempo que se vem investigando arqueologicamente o Castelo de São Jorge, sendo de elementar justiça destacar o trabalho continuado de Alexandra Gaspar e Ana Gomes na Praça Nova ${ }^{12}$, ao abrigo do Projecto Integrado do Castelo de São Jorge, cujos resultados levaram à definição de uma área arqueológica visitável e do Núcleo Museológico do Castelo de São Jorge ${ }^{13}$. Neste momento, a investigação sobre a fortaleza prepara-se para entrar numa nova fase. Estão em curso projectos académicos de investigação destinados a estudar a fortificação na fase muçulmana - para a qual foi essencial a recente leitura de Carmen Barceló de uma inscrição islâmica do Museu de Lisboa $^{14}$ - e a resgatar abundante informação documental inédita sobre a história e o restauro do monumento. Paralelamente, o estudo físico das muralhas e torres do castelo está a revelar-se uma verdadeira surpresa, como se comprova pela leitura do esgrafito que alude ao terramoto de 1356 , recentemente

\footnotetext{
${ }^{12}$ GASPAR, Alexandra; GOMES, Ana - "Castelo de São Jorge - balanço e perspectivas dos trabalhos arqueológicos". Revista Estudos, n. 4 (2003), pp. 214-223.

${ }^{13}$ SERRA, Susana - Castelo de São Jorge. Núcleo Museológico. Lisboa: EGEAC, 2008.

${ }^{14}$ BARCELÓ, Carmen - "Lisboa y Almanzor (374H. / 985 d.C.)". Conimbriga, n. 57 (2013), pp. 165194.
} 
efectuada por Bernardo Sá Nogueira ${ }^{15}$, e pelos muitos materiais de várias épocas que se encontram incorporados nos muros, formando parte dos seus enchimentos.

Sendo o Castelo de São Jorge um monumento cuja autenticidade tantas vezes se questiona, pela radicalidade da intervenção pretensamente restauradora realizada entre 1938 e 1942 - intervenção, de resto, que carece de um estudo monográfico rigoroso -, estas descobertas representam novos motivos para o desenvolvimento de um plano de investigação integral do conjunto monumental, ao mesmo tempo que transmitem a sensação de que se deve voltar ao ponto de partida e começar a estudar o castelo do princípio, sem aceitar pré-conceitos acerca da originalidade das suas parcelas, do carácter inventivo do restauro ou da profundidade com que se afectou o subsolo e os seus estratos arqueológicos.

Por estes motivos, importa que, em paralelo com o estudo documental, fotográfico e iconográfico do restauro, se possam desenvolver projectos complementares de diagnóstico e de caracterização. É essencial que se promova um levantamento exaustivo dos paramentos das muralhas e das torres e que se complete esse trabalho com uma análise de arqueologia da arquitectura. E é também importante que a arqueologia convencional volte ao topo da colina, porque a área arqueológica da Praça Nova é um dos motivos de atractividade do castelo, mas também porque há um imperativo científico no estudo de zonas potencialmente relevantes, em particular associadas aos alicerces de alguns sectores do sistema defensivo e de outras parcelas da alcáçova.

Neste cenário, o Instituto de Estudos Medievais desempenha já papel importante, tendo sido firmados protocolos com a EGEAC (empresa gestora do Castelo de São Jorge) para permitir investigações de mestrado e de doutoramento sobre a alcáçova medieval de Lisboa (2014), tendo havido já sessões de debate e de transferência de conhecimento, como o 1. ${ }^{\circ}$ Workshop sobre a alcáçova e o castelo de Lisboa (Junho de 2015) e prevendo-se mais acções num futuro próximo.

${ }^{15}$ PEREIRA, Gonçalo - "Crónicas do Castelo". National Geographic Portugal (Jan. 2016), pp. 20-31. 
Habituámo-nos a caracterizar o sistema defensivo de Lisboa nos seus três monumentosetapas fundamentais: Castelo de São Jorge; Cerca Velha e Cerca Fernandina. Mas nem essas estruturas funcionam de forma isolada, nem são o resultado de campanhas construtivas temporalmente unitárias, nem, tão pouco, são os únicos elementos de um sistema militar que contou com outras realizações e outros momentos. A visibilidade arqueológica do muro do tempo de D. Dinis ou o lanço de muralha que avança da Cerca Velha até à Torre de São Pedro provam como a defesa da cidade foi um processo continuado, conjunturalmente avaliado em cada época, cujas etapas de construção são mais numerosas e carecem de um estudo tipológico concertado. É nesse sentido que o trabalho de Artur Rocha no subsolo do Banco de Portugal deve ser articulado com as acções de Manuela Leitão na Cerca Velha e com os de Ana Gomes no Castelo de São Jorge, a que se devem juntar muitos outros autores que têm vindo a investigar, de forma parcelar, aqueles monumentos. Mas é também importante que exista um plano integrado para todo este património, no qual se inclua ainda a Cerca Fernandina e as sondagens mais ou menos isoladas que têm sido realizadas ao longo do seu percurso ${ }^{16}$.

Finalizo com uma palavra sobre a excelente museografia do Núcleo de Interpretação da Muralha de D. Dinis. A visita é antecedida por uma animação gráfica relativamente simples mas muito didáctica, que passa em revista, em poucos segundos, a evolução da cidade desde a época medieval até aos nossos dias e as diferentes opções construtivas que foram tomadas para o local onde hoje se encontra o Banco de Portugal. A descida à muralha propriamente dita é acompanhada por um percurso descendente também em termos cronológicos, do mais recente para o mais antigo, que simula, em certa medida, a própria evolução de uma escavação arqueológica, ao longo do qual o visitante toma contacto com artefactos e outros objectos encontrados pelos arqueólogos. O espólio é limitado e de importância reduzida, mas as soluções de exposição encontradas, a que não faltam animações tridimensionais das peças, merecem ser elogiadas. Finalmente, o percurso pela muralha é acompanhado por discretas tabelas explicativas que contextualizam não só a história da muralha, mas também as muitas cicatrizes que os

16 "Escavações arqueológicas em curso junto ao miradouro da Graça em Lisboa". Diário de Notícias (14 Ago. 2015). Aguarda-se também com expectativa a publicação de resultados da escavação que António Valongo coordenou na Rua do Arsenal, onde se identificou uma das mais importantes torres da muralha fernandina. 
tempos posteriores deixaram, assim indicando aos visitantes que estão a observar um muro que, longe de alguma vez ter estado cristalizado no tempo, antes foi aproveitado para diversos fins ao longo da História, sendo a sua musealização apenas mais um momento. E isto é uma das coisas que se conseguem quando se junta dinheiro, competência e bom gosto.

\section{COMO CITAR ESTE ARTIGO}

\section{Referência electrónica:}

FERNANDES, Paulo Almeida - "Recensão: ROCHA, Artur - A Muralha de D. Dinis e a Cidade de Lisboa. Fragmentos Arqueológicos e a Evolução Histórica. Lisboa: Museu do Dinheiro / Banco de Portugal, 2015 (60 pp.)”. Medievalista [Em linha]. N. 20 (Julho - Dezembro 2016). [Consultado dd.mm.aaaa]. Disponível em http://www2.fcsh.unl.pt/iem/medievalista/MEDIEVALISTA20/fernandes2009.html ISSN 1646-740X.

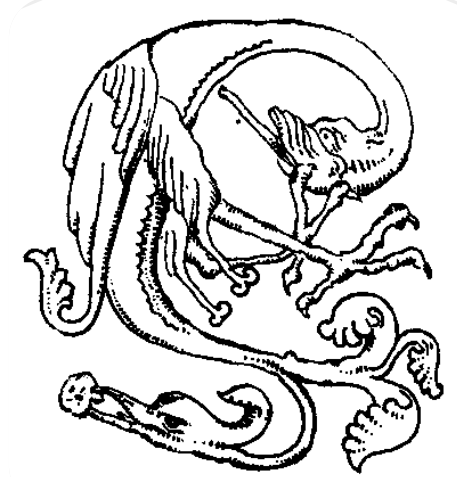

